\title{
Effect of feed sorting on chewing behavior, production, and rumen fermentation in lactating dairy cows ${ }^{1}$
}

\author{
D. D. Maulfair, ${ }^{*}$ G. I. Zanton, ${ }^{*}$ M. Fustini, $†$ and A. J. Heinrichs ${ }^{* 2}$ \\ *Department of Dairy and Animal Science, The Pennsylvania State University, University Park 16802 \\ †Facoltá di Medicina Veterinaria, Universitá di Bologna, Bologna 40064, Italy
}

\begin{abstract}
Ration sorting is thought to allow cows to eat different rations throughout the day, causing fluctuations in rumen fermentation patterns that can be detrimental to production and possibly animal health. The objective of this experiment was to study the effects of varying total mixed ration (TMR) particle size on sorting behavior of lactating dairy cows and to evaluate effects on chewing behavior, milk yield, milk components, and rumen fermentation. Eight multiparous, Holstein cows (90 $\pm 32 \mathrm{~d}$ in milk; 4 rumen cannulated) were randomly assigned to replicated $4 \times 4$ Latin squares. Cows were fed diets that varied in the chop length of dry grass hay. The diet consisted of $29.4 \%$ corn silage, $22.9 \%$ ground corn, $17.6 \%$ alfalfa haylage, and $11.8 \%$ dry grass hay on a dry matter basis. The percentage of hay particles $>26.9 \mathrm{~mm}$ was $4.2,34.1,60.4$, and $77.6 \%$ for the short (S), medium (M), long (L), and extra long (XL) hays, respectively. This resulted in the TMR of each diet having $1.5(\mathrm{~S}), 6.5(\mathrm{M}), 8.6(\mathrm{~L})$, and $11.7 \%$ (XL) of particles $>26.9 \mathrm{~mm}$. Daily ruminating time $[19.3,19.2,22.4$, and $21.3 \mathrm{~min} / \mathrm{kg}$ of dry matter intake (DMI) for S, M, L, and XL] and eating time (13.9, 14.6, 17.2 , and $16.1 \mathrm{~min} / \mathrm{kg}$ of $\mathrm{DMI}$ for S, M, L, and XL) increased linearly as TMR particle size increased. Daily DMI decreased linearly as TMR particle size increased and was $26.9(\mathrm{~S}), 27.0(\mathrm{M}), 24.1(\mathrm{~L})$, and 25.1 (XL) $\mathrm{kg} / \mathrm{d}$. No differences were found in rumen volatile fatty acids and $\mathrm{NH}_{3}$, and only slight changes were found in rumen $\mathrm{pH}$. Milk production and milk components were also similar among diets. Despite large differences in particle size among these diets and certain chewing and ruminating differences, no changes in rumen fermentation, milk production, or milk components were found in this study.
\end{abstract}

Received March 20, 2010.

Accepted May 24, 2010.

${ }^{1}$ This research was a component of NC-1042, Management Systems to Improve the Economic and Environmental Sustainability of Dairy Enterprises.

${ }^{2}$ Corresponding author: ajh@psu.edu
Key words: chewing, particle size, rumination, sorting

\section{INTRODUCTION}

The NRC (2001) recommends a minimum NDF level of $25 \%$ of DM and a forage NDF level of $19 \%$ of DM for lactating dairy cows. However, the NRC states that these values are based on cows fed a TMR, alfalfa or corn silage as the predominant forage, forage with adequate particle size, and dry ground corn as the predominant starch source. These recommendations are therefore limited to rather specific conditions because of the limited data available, and they do not define adequate particle size in a measurable manner. Fiber with adequate length is thought to increase chewing in cattle, which increases salivary secretion of $\mathrm{NaHCO}_{3}$ and buffers the rumen digesta (Allen, 1997; Nocek, 1997; Krause et al., 2002b). Beauchemin et al. (2008) showed that rate $(\mathrm{g} / \mathrm{min})$ of salivation stayed constant during eating; however, changes in the rate of eating affected the amount of saliva secreted per unit of DMI when cows were fed barley silage, alfalfa silage, long-stemmed alfalfa hay, or barley straw. Particle size, DM, and NDF content of forages are factors affecting rate of eating and time spent eating (Bailey, 1961; Beauchemin et al., 2008) and it has been suggested that time spent chewing is a good measure of a feed's physical effectiveness (Balch, 1971; Sudweeks et al., 1981). Physically effective NDF (peNDF), which combines the physical and chemical properties of a feedstuff, is commonly defined as the NDF concentration multiplied by the percentage of particles retained on a $1.18-\mathrm{mm}$ sieve $(1.65-\mathrm{mm}$ screen diagonal) and greater. This definition presumes that the cows consume the ration as formulated.

Dairy cows have been shown to selectively consume or sort their rations when fed a TMR. Cows generally sort against long particles and for finer particles (Kononoff et al., 2003b; Leonardi and Armentano, 2003; DeVries et al., 2007). This is thought to create problems because not only are they reducing the particle size of the diet consumed, they are also reducing NDF intake as the longer particles of the TMR contain 
a higher proportion of NDF than the rest of the ration (Leonardi and Armentano, 2003). Feeding longer alfalfa hay versus chopped alfalfa hay increased sorting of rations, but intake of long particles still increased when cows were fed the long alfalfa hay because of the higher concentration in the diet (Leonardi and Armentano, 2003). A potential problem for dealing with sorting on dairy farms is the fact that variability of sorting among cows can be very substantial, especially with the longest fraction (Leonardi and Armentano, 2003; Leonardi et al., 2005a).

Therefore, the objective of this experiment was to study the effects of varying TMR particle size on sorting behavior and to evaluate its effects on chewing behavior, milk yield, milk components, and rumen fermentation in lactating dairy cows.

\section{MATERIALS AND METHODS}

\section{Diets, Cows, and Experimental Design}

Cows used in this research were cared for and maintained according to a protocol approved by The Pennsylvania State University Institutional Animal Care and Use Committee. Eight lactating, multiparous, Holstein cows averaging $90 \pm 32$ DIM, weighing $642 \pm$ $82 \mathrm{~kg}$, and with parity of $2.25 \pm 0.46$ (mean $\pm \mathrm{SD}$ ) were randomly assigned to replicated $4 \times 4$ Latin squares; 1 square contained rumen-cannulated cows. The periods were $21 \mathrm{~d}$ in length, with a 13-d adaptation period followed by an 8-d collection period.

During each of the 4 periods, cows were fed 1 of 4 rations that contained identical feed ingredients and proportions but varied in the length of the dry grass hay included in the ration. Ingredients and their percentage of ration DM were corn silage (29.4), ground corn (22.9), haylage (17.6), grass hay (11.8), roasted soybeans (6.7), canola meal (5.7), heat-treated soybean meal (3.2), mineral/vitamin mix (2.4), and salt (0.3). The mineral and vitamin mix contained $12.2 \%$ $\mathrm{Ca}, 0.41 \% \mathrm{P}, 3.88 \% \mathrm{Mg}, 0.48 \% \mathrm{~K}, 0.37 \% \mathrm{~S}, 3.54 \% \mathrm{Na}$, $5.46 \% \mathrm{Cl}, 222 \mathrm{mg} / \mathrm{kg}$ of Fe, $1,379 \mathrm{mg} / \mathrm{kg}$ of Zn, $455 \mathrm{mg} /$ $\mathrm{kg}$ of $\mathrm{Cu}, 1,363 \mathrm{mg} / \mathrm{kg}$ of $\mathrm{Mn}, 11.2 \mathrm{mg} / \mathrm{kg}$ of Se, 7.33 $\mathrm{mg} / \mathrm{kg}$ of Co, $18.5 \mathrm{mg} / \mathrm{kg}$ of I, $298 \mathrm{kIU} / \mathrm{kg}$ of vitamin A, $73.9 \mathrm{kIU} / \mathrm{kg}$ of vitamin $\mathrm{D}, 2,853 \mathrm{IU} / \mathrm{kg}$ of vitamin E. The grass hay inclusion level (20\% of forage DM) was chosen based on previous research that showed it allowed for rations to be properly balanced while still creating adequate variations in particle size distributions between rations. Grass hay lengths of short $(\mathbf{S})$, medium (M), long (L), and extra long (XL) were produced using several bale choppers. The XL and L hay was chopped once and twice, respectively, with a Case IH model 8610 bale processor (Case IH, Racine,
$\mathrm{WI}$ ). The $\mathrm{M}$ and $\mathrm{S}$ hays were chopped 1 and 3 times, respectively, with a Roto Grind model 760 tub grinder (Burrows Enterprises Inc., Greeley, CO); the S hay was additionally run once through a New Holland model 718 forage harvester (New Holland Ag, Racine, WI). All diets were mixed separately using an I. H. Rissler model 1050 TMR mixer (E. Rissler Mfg. LLC, New Enterprise, PA).

Animals were housed in individual stalls, milked twice a day at 0700 and $1900 \mathrm{~h}$ and fed once a day at approximately $0730 \mathrm{~h}$ for ad libitum consumption and for $10 \%$ refusal to allow extensive opportunity to sort the ration. Feed was pushed up 3 times/d at 1230 , 1730 , and $2400 \mathrm{~h}$. All rations were balanced to meet or exceed NRC (2001) requirements and water was available for ad libitum consumption.

\section{Chewing Activity}

Eating and ruminating activity were recorded on d 14 through 18 of each period using Institute of Grassland and Environmental Research Behavior Recorders and Graze Jaw Movement Analysis Software (Ultra Sound Advice, London, UK) as described by Rutter et al. (1997) and Rutter (2000). These recorders analyze jaw movements of cattle and the software can determine eating or ruminating chews based on the amplitude and frequency of jaw movements. This procedure has been validated for use with cows housed in tie-stalls by Kononoff et al. (2002). Chewing was measured for all cows for two 24-h periods including while cows were being milked.

Intermeal intervals were separated from intrameal intervals by analysis of the $2 \mathrm{~d}$ of chewing data (minimum interval $\geq 4 \mathrm{~s}$ ) by a modification of the methodology reported by Tolkamp et al. (1998) and Yeates et al. (2001). Initial analysis of the probability density functions (PDF) of all data revealed that inter- and intrameal histograms were each skewed toward the point that these histograms crossed. Yeates et al. (2001) reported that a Weibull distribution fitted to the last population of intervals adequately accounted for the skewness observed in that data set, whereas skewness in the first population was subdivided into 2 populations of intervals associated with drinking and nondrinking within-meal intervals. To account for the skewness present in the current data set, a Weibull distribution was fit to both populations to avoid potential overparameterization and allow for a skewed representation of the data. Because the methodology employed is based upon the concept of satiety and the treatments administered in the current experiment were hypothesized to affect meal responses, a meal criterion estimate for the treatments that could be evaluated for statistical dif- 
ferences would be of value. Frequently, meal criteria are estimated from pooled or individual cow data; however, a Latin square experimental design with treatments applied over periods and cows limits the appropriateness of pooling the data. Because parameter estimates resulting from analysis of the individual cow within period replicates are not estimated from the data without error or correlation, a nonlinear mixed model methodology was employed to estimate parameters while explicitly accounting for the design of the experiment within the framework of the nonlinear estimation procedure. The following Weibull mixture model was fit to the observed cumulative frequencies (grouped by 0.1 $\log _{\mathrm{e}}$ second intervals; CDF) using the nonlinear mixed procedure in SAS (SAS Institute, 2006) using adaptive Gaussian quadrature with the Laplace approximation to the marginal likelihood:

$$
\begin{aligned}
C D F_{j k l} & =p \times\left(1-e^{-\left(\frac{\gamma_{1}-1}{\gamma_{1}}\right) \times\left(\frac{t}{m_{1}}\right)^{\gamma_{1}}}\right) \\
& +(1-p) \times\left(1-e^{-\left(\frac{\gamma_{2}-1}{\gamma_{2}}\right) \times\left(\frac{t}{m_{2}}\right)^{\gamma_{2}}}\right)+\varepsilon_{j k l},
\end{aligned}
$$

where

$$
p=\frac{a_{2}}{a_{1}+a_{2}},
$$

and

$$
a_{i=1,2}=\left(\gamma_{i}-1\right) \times\left(\frac{t_{c}}{m_{i}}\right)^{\gamma_{i}} \times e^{-\left(1-\frac{1}{\gamma_{i}}\right) \times\left(\frac{t_{c}}{m_{i}}\right)^{\gamma_{i}}} ;
$$

$t=\log _{\mathrm{e}}$ (interval time) $; \gamma_{i=1,2}=$ coefficient of the shape parameter of the Weibull distribution for the first or second population, respectively; $m_{i=1,2}=$ coefficient of the time point of inflection of the CDF and mode (maximum frequency) of the PDF for the first or second population, respectively; $t_{c}=$ coefficient of the meal criterion; $\varepsilon_{j k l}=$ random error component $\sim \mathrm{N}\left[0, V^{2}\right]$, with

$$
V^{2}=\sigma^{2} \times\left[\begin{array}{l}
p \times\left(\frac{\left(\gamma_{1}-1\right)}{t} \times\left(\frac{t}{m_{1}}\right)^{\gamma_{1}} \times e^{\left.-\left(1-\frac{1}{\gamma_{1}}\right) \times\left(\frac{t}{m_{1}}\right)^{\gamma_{1}}\right)}\right. \\
+(1-p) \times\left(\frac{\left(\gamma_{2}-1\right)}{t} \times\left(\frac{t}{m_{2}}\right)^{\gamma_{2}} \times e^{-\left(1-\frac{1}{\gamma_{2}}\right) \times\left(\frac{t}{m_{2}}\right)^{\gamma_{2}}}\right.
\end{array}\right] ;
$$

that is, the residual standard deviation is weighted by the squared root of the PDF. Additionally, each coefficient is the sum of the overall mean parameter estimate across period, treatment, and cow; the fixed effects of period and treatment; and the random effect of cow:

$$
Z_{j k l}=Z+Z P_{j}+Z T_{k}+z c_{l}
$$

where $Z_{j k l}=$ generic coefficient of the Weibull mixture model; $Z$ = estimate of coefficient $Z$ across periods, treatments, and cows; $Z P_{j}=$ fixed effect of period $j$ on $\mathrm{Z}(j=1,2,3,4)$ subject to the constraint that $\Sigma Z P_{j}=$ $0 ; Z T_{k}=$ fixed effect of treatment $k$ on $\mathrm{Z}(k=1,2,3,4)$ subject to the constraint that $\Sigma Z T_{k}=0 ; z c_{l}=$ random effect of cow $l$ on $\mathrm{Z}(l=1, \ldots, 8) \sim \mathrm{N}\left[0, \sigma_{\mathrm{c}}{ }^{2}\right]$.

The model used to calculate meal criteria in this experiment was different from that used by Yeates et al. (2001) in 3 ways: 1) the CDF was fit with the nonlinear mixed procedure based on maximum likelihood estimation of the parameters; 2) the scale parameter of the Weibull distribution was replaced by the expected value parameter of the mode of the PDF or the time point of inflection of the CDF; 3 ) the parameter estimate of $p$ (the proportion of intervals in the first population) was replaced by the expected value parameter for the time when the PDF of the 2 populations intersected (i.e., the meal criterion $t_{c}$ ) so that the meal criteria could be explicitly estimated concurrently with the remaining coefficients of the model. Additionally, the studentized residuals were observed to be heteroscedastic across time and appeared to vary in association with the PDF. Thus, the variance was weighted by the PDF, which removed the heteroscedasticity. The parameter $\gamma_{2}$ was observed to be a far-from-linear parameter according to the Hougaard skewness calculation; a substitution of $\log _{\mathrm{e}} \gamma_{2}$ for $\gamma_{2}$ was found to make the estimate close-tolinear and improve the estimates of the parameters. The variance-covariance matrix of the random effects was initially considered to be unstructured; however, the only covariance parameter estimate that significantly contributed to model fit (by the Bayesian information criterion) was between $m_{1}$ and $\gamma_{1}$; thus, only this covariance parameter was retained in the final fitting of the model. An overall test of the significance of a treatment effect on each of the parameters of the model was carried out by fitting the full and reduced model and using the likelihood ratio test. Predicted values for $t_{c}$ were computed using the parameter estimates and empirical Bayes estimates of the random effects; the number of meals was then calculated as the sum of intervals exceeding the predicted meal criterion within cow and period. Least squares means and standard errors of the within-treatment parameter estimates were calculated 
from the solutions and the variance-covariance matrix for the nonlinear mixed model, respectively. Results were back-transformed differences between treatments evaluated using the $95 \%$ confidence intervals of the least squares means.

Meal criteria intervals of 5 and 7 min were evaluated in addition to the calculated meal criteria. The 5-min interval was used for comparison to studies that used manual observation (Maekawa et al., 2002; Beauchemin et al., 2003; Leonardi et al., 2005b) or video observation (Bhandari et al., 2008) at 5-min intervals to determine chewing activity. The 7-min meal criterion was used because it is the default intermeal interval for the Graze program (Rutter, 2000), and it is similar to that used in research from several studies (Dado and Allen, 1993; Mooney and Allen, 2007) that used $7.5 \mathrm{~min}$.

\section{Rumen Sampling}

On d 15 of each period, ruminal contents were collected from dorsal, ventral, cranial, caudal, and medial areas of the rumen at $0.0,1.5,3.5,5.5,8.5,11.5,14.5,18$, 21.5, and $24.5 \mathrm{~h}$ after feeding (Kononoff et al., 2003b). Collected digesta were mixed thoroughly, sampled, and filtered through 4 layers of cheesecloth. Rumen liquid $\mathrm{pH}$ was immediately determined using a handheld $\mathrm{pH}$ meter (phTestr 10 BNC, Oakton, Vernon Hills, IL). Approximately $15 \mathrm{~mL}$ of filtered liquid was placed into bottles containing $3 \mathrm{~mL}$ of $25 \%$ metaphosphoric acid and $3 \mathrm{~mL}$ of $0.6 \%$ 2-ethylbutyric acid (internal standard) and stored at $-20^{\circ} \mathrm{C}$. After thawing, samples were centrifuged 3 times at $4,000 \times g$ for 30 min at $4^{\circ} \mathrm{C}$ to obtain a clear supernatant and were analyzed for $\mathrm{NH}_{3}$ using a phenol-hypochlorite assay (Broderick and Kang, 1980) and VFA concentration using gas chromatography (Yang and Varga, 1989).

\section{Feed, Refusal, and Particle Size Analysis}

Feed bunk contents for each animal were weighed and sampled on d 20 and 21 at $0,2,4,8,12,16$, and $24 \mathrm{~h}$ after feeding to determine particle size distribution and $\mathrm{DM}$ of the remaining feed. At $0,8,16$, and $24 \mathrm{~h}$ after feeding, refusals were also analyzed for NDF and starch content to determine intake of these components between each time point. All samples were sieved in the American Society of Agriculture and Biological Engineers (ASABE) forage particle separator, which can determine 6 particle fractions $(>26.9,>18.0$, $>8.98,>5.61,>1.65$, and $<1.65 \mathrm{~mm}$; screen diagonal; ASABE., 2007). Because $>1 \%$ of material was retained on the top screen, 3 samples of each diet were randomly selected and all particles retained on the top screen were measured manually (with a ruler) before drying. Whole samples were then placed in a forced air oven at $55^{\circ} \mathrm{C}$ for $48 \mathrm{~h}$ to determine DM content. Geometric mean particle length $\left(\mathbf{X}_{\mathbf{g m}}\right)$ and standard deviation of the particle length $\left(\mathbf{S}_{\mathrm{gm}}\right)$ were calculated according to the ASABE (2007) procedure. Samples were then ground (1-mm screen; Wiley mill, Arthur H. Thomas Co. Inc., Swedesboro, NJ) to determine NDF using heat-stable $\alpha$-amylase and $\mathrm{Na}_{2} \mathrm{SO}_{3}$ according to Van Soest et al. (1991) and ground (0.5-mm screen; Wiley mill, Arthur H. Thomas Co. Inc.) to analyze starch using a modified procedure from Knudsen (1997). Samples of forages and TMR were taken 3 times/wk, composited by period, and analyzed by Cumberland Valley Analytical Services Inc. (Hagerstown, MD) for $\mathrm{CP}, \mathrm{ADF}, \mathrm{NDF}$, ash, $\mathrm{NFC}$, and $\mathrm{NE}_{\mathrm{L}}$. Two procedures were used to calculate peNDF; peNDF ${ }_{8.0}=\%$ of particles $>8.98 \mathrm{~mm} \times \mathrm{NDF}$ of whole sample (similar to top 2 sieves of PSPS) and peNDF $_{1.18}=\%$ of particles $>1.65 \mathrm{~mm} \times \mathrm{NDF}$ of whole sample (similar to top 3 sieves in PSPS) (Kononoff et al., 2003a). A sorting index based on the refusals was calculated for the particle size fractions at 2, 4, 8, 12, 16 , and $24 \mathrm{~h}$ after feeding and for NDF and starch at 8,16 , and $24 \mathrm{~h}$ after feeding. Sorting activity was calculated as the actual intake of each fraction ( $\mathrm{Y}_{1}$ to pan) expressed as a percentage of the expected intake. Expected intake of $Y_{i}$ equals intake multiplied by the fraction of $Y_{i}$ in the TMR (Leonardi and Armentano, 2003). Sorting indices were calculated using both the expected intake since time point 0 (cumulative) and the expected intake since the previous time point (interval). Additionally, $\mathrm{X}_{\mathrm{gm}}$ sorting indices were calculated for the same time points by dividing the $\mathrm{X}_{\mathrm{gm}}$ of TMR consumed up to each time point by $\mathrm{X}_{\mathrm{gm}}$ at time 0 . Values $>1$ indicate that cows were consuming rations with longer particle size and values $<1$ indicate cows were consuming rations with shorter particle size than the diets fed.

\section{Milk Production}

Milk production was recorded and samples were taken on d 20 and 21 at morning and evening milkings. Samples were collected and preserved using 2-bromo-2nitropropane-1,3 diol. Milk samples were analyzed for fat, true protein, lactose, MUN, and SCC by the Dairy One milk testing laboratory (State College, PA) using infrared spectrophotometry (Foss 605B MilkoScan, Foss Electric, Hillerød, Denmark).

\section{Statistical Analyses}

Statistical analysis was conducted using PROC MIXED of SAS (SAS Institute, 2006). Dependent variables were analyzed as a $4 \times 4$ Latin square design. All 
Table 1. Chemical composition and particle size distributions determined with the ASABE particle separator for corn silage, alfalfa haylage, and short $(\mathrm{S})$, medium $(\mathrm{M})$, long (L), or extra long (XL) grass hay

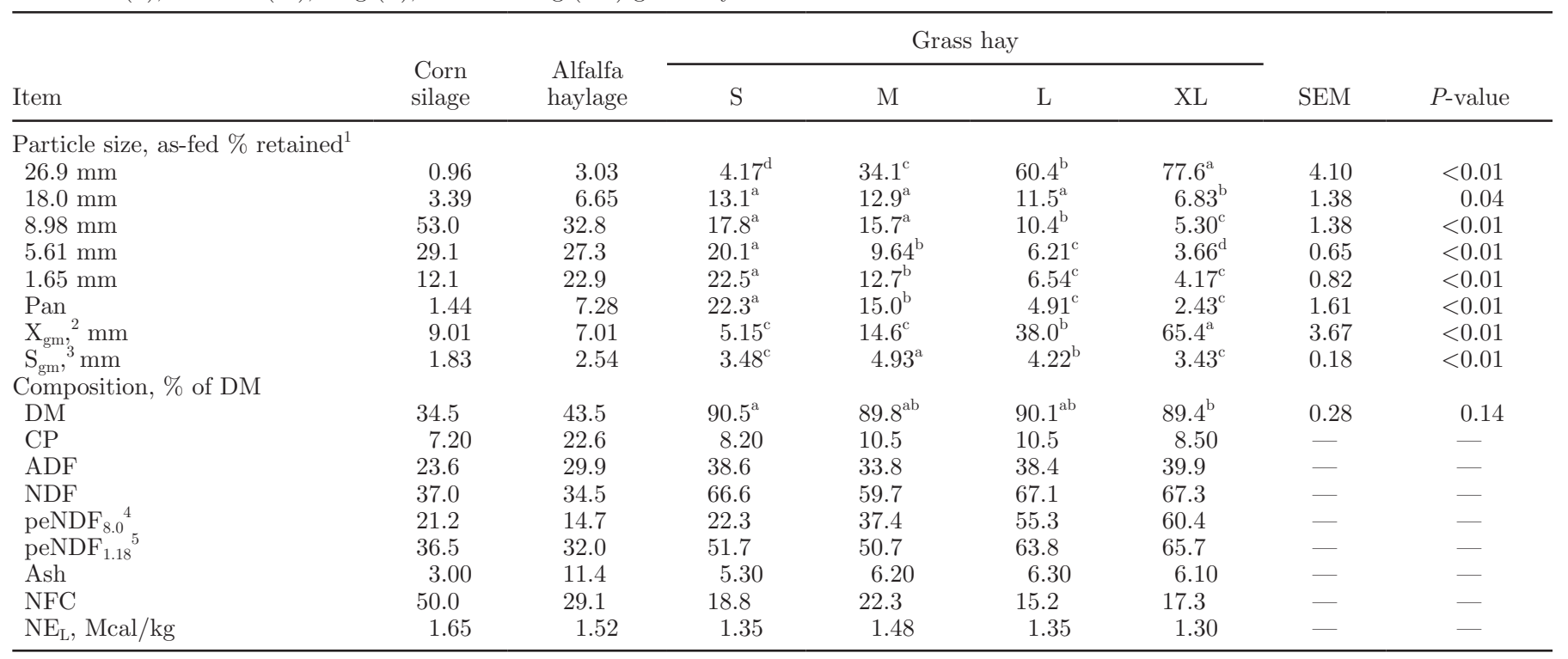

${ }^{\mathrm{a}-\mathrm{d}}$ Means within a row with different superscripts differ $(P<0.05)$.

${ }^{1}$ Approximate equivalency to Penn State Particle Separator (PSPS): top sieve $(26.9+18.0 \mathrm{~mm})$, middle sieve $(8.98 \mathrm{~mm})$, lower sieve $(5.61+$ $1.65 \mathrm{~mm}$ ), and pan (pan).

${ }^{2} \mathrm{X}_{\mathrm{gm}}=$ geometric mean particle length determined by ASABE (2007).

${ }^{3} \mathrm{~S}_{\mathrm{gm}}=$ particle length standard deviation determined by ASABE (2007).

${ }^{4}$ Physically effective $\mathrm{NDF}_{8.0}=\%$ of particles $>8.98 \mathrm{~mm} \times \mathrm{NDF}$ of whole sample (similar to top 2 sieves of PSPS) (Kononoff et al., 2003a).

${ }^{5}$ Physically effective $\mathrm{NDF}_{1.18}=\%$ of particles $>1.65 \mathrm{~mm} \times \mathrm{NDF}$ of whole sample (similar to top 3 sieves in PSPS) (Kononoff et al., 2003a).

Table 2. Chemical composition and particle size distributions determined with the ASABE particle separator for TMR containing short (S), medium $(\mathrm{M})$, long $(\mathrm{L})$, or extra long (XL) grass hay

\begin{tabular}{|c|c|c|c|c|c|c|c|}
\hline Item & S & M & $\mathrm{L}$ & XL & SEM & Linear & Quadratic \\
\hline $26.9 \mathrm{~mm}$ & 1.47 & 6.52 & 8.61 & 11.7 & 0.52 & $<0.01$ & 0.31 \\
\hline $5.61 \mathrm{~mm}$ & 22.6 & 20.9 & 21.0 & 20.2 & 0.29 & $<0.01$ & 0.22 \\
\hline $1.65 \mathrm{~mm}$ & 25.1 & 23.6 & 23.7 & 23.4 & 0.34 & $<0.01$ & 0.15 \\
\hline Pan & 22.3 & 22.2 & 22.6 & 22.3 & 0.48 & 0.92 & 0.91 \\
\hline \multicolumn{8}{|c|}{ Composition, $\%$ of DM } \\
\hline DM, \% & 55.1 & 56.4 & 56.3 & 57.0 & 0.56 & 0.02 & 0.67 \\
\hline $\mathrm{CP}$ & 15.8 & 15.9 & 16.0 & 16.1 & 0.24 & 0.31 & 0.94 \\
\hline $\mathrm{ADF}$ & 22.3 & 22.5 & 21.7 & 23.0 & 0.30 & 0.26 & 0.12 \\
\hline $\mathrm{NDF}$ & 33.7 & 34.2 & 34.0 & 34.3 & 0.40 & 0.41 & 0.83 \\
\hline Forage NDF & 24.8 & 24.0 & 24.8 & 24.9 & - & - & - \\
\hline $\operatorname{peNDF}_{80}{ }^{4}$ & 10.2 & 11.4 & 11.1 & 11.7 & 0.39 & 0.03 & 0.43 \\
\hline
\end{tabular}

${ }^{1}$ Approximate equivalency to Penn State Particle Separator (PSPS): top sieve $(26.9+18.0 \mathrm{~mm})$, middle sieve $(8.98 \mathrm{~mm})$, lower sieve $(5.61+$ $1.65 \mathrm{~mm})$, and pan (pan).

${ }^{2} \mathrm{X}_{\mathrm{gm}}=$ geometric mean particle length determined by ASABE (2007).

${ }^{3} \mathrm{~S}_{\mathrm{gm}}=$ particle length standard deviation determined by ASABE (2007).

${ }^{4}$ Physically effective $\mathrm{NDF}_{8.0}=\%$ of particles $>8.98 \mathrm{~mm} \times \mathrm{NDF}$ of whole sample (similar to top 2 sieves of PSPS) (Kononoff et al., 2003a).

${ }^{5}$ Physically effective $\mathrm{NDF}_{1.18}=\%$ of particles $>1.65 \mathrm{~mm} \times \mathrm{NDF}$ of whole sample (similar to top 3 sieves in PSPS) (Kononoff et al., 2003a). 


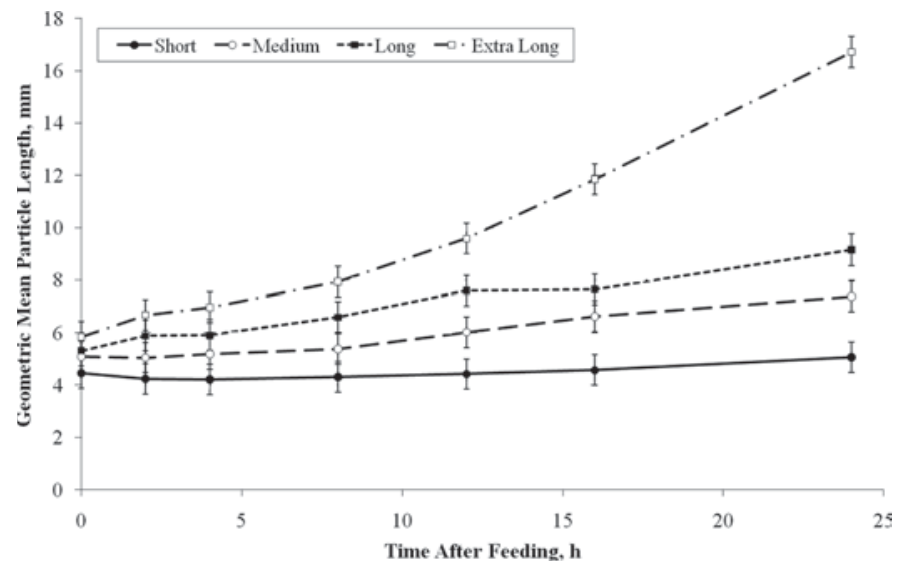

Figure 1. Effect of feeding TMR of increasing particle size on refusal geometric mean particle size.

denominator degrees of freedom for $F$-tests were calculated according to Kenward and Roger (1997), and repeated measurements for rumen samples and refusal particle size, NDF, and starch were analyzed using the first-order autoregressive covariance structure (Littell et al., 1998), as well as terms for time and interaction of treatment by time. Because of unequally spaced rumen sampling, the weighted mean daily $\mathrm{pH}, \mathrm{NH}_{3}$, and VFA concentrations were determined by calculating the area under the response curve according to the trapezoidal rule (Shipley and Clark, 1972). The data were analyzed for orthogonal contrasts using the fed TMR $\mathrm{X}_{\mathrm{gm}}$ that was corrected for unequal spacing according to Robson (1959). All data are presented as least squares means, and treatment effects are considered significant when $P$ $<0.05$ and a trend when $P<0.10$.

\section{RESULTS AND DISCUSSION}

\section{Chemical Composition and Particle Size Distribution}

The chemical composition, particle size distribution, and $\mathrm{X}_{\mathrm{gm}}$ of forages included in the rations are shown in Table 1. Particle size was determined with the ASABE forage particle separator because the particle length of some diets was so great that the Penn State Particle Separator (PSPS) did not adequately separate samples. The PSPS particle fractions and their approximate equivalent ASABE separator screens are as follows: top $(26.9+18.0 \mathrm{~mm})$, middle $(8.98 \mathrm{~mm})$, lower $(5.61+1.61 \mathrm{~mm})$, and pan (pan). The grass hays had large differences in particle size, particularly with the particles retained on the $26.9-\mathrm{mm}$ screen although all particle fractions had differences among the hays. In addition, the $\mathrm{X}_{\mathrm{gm}}$ increased greatly from the shortest to the longest ration, with a 13 -fold difference between
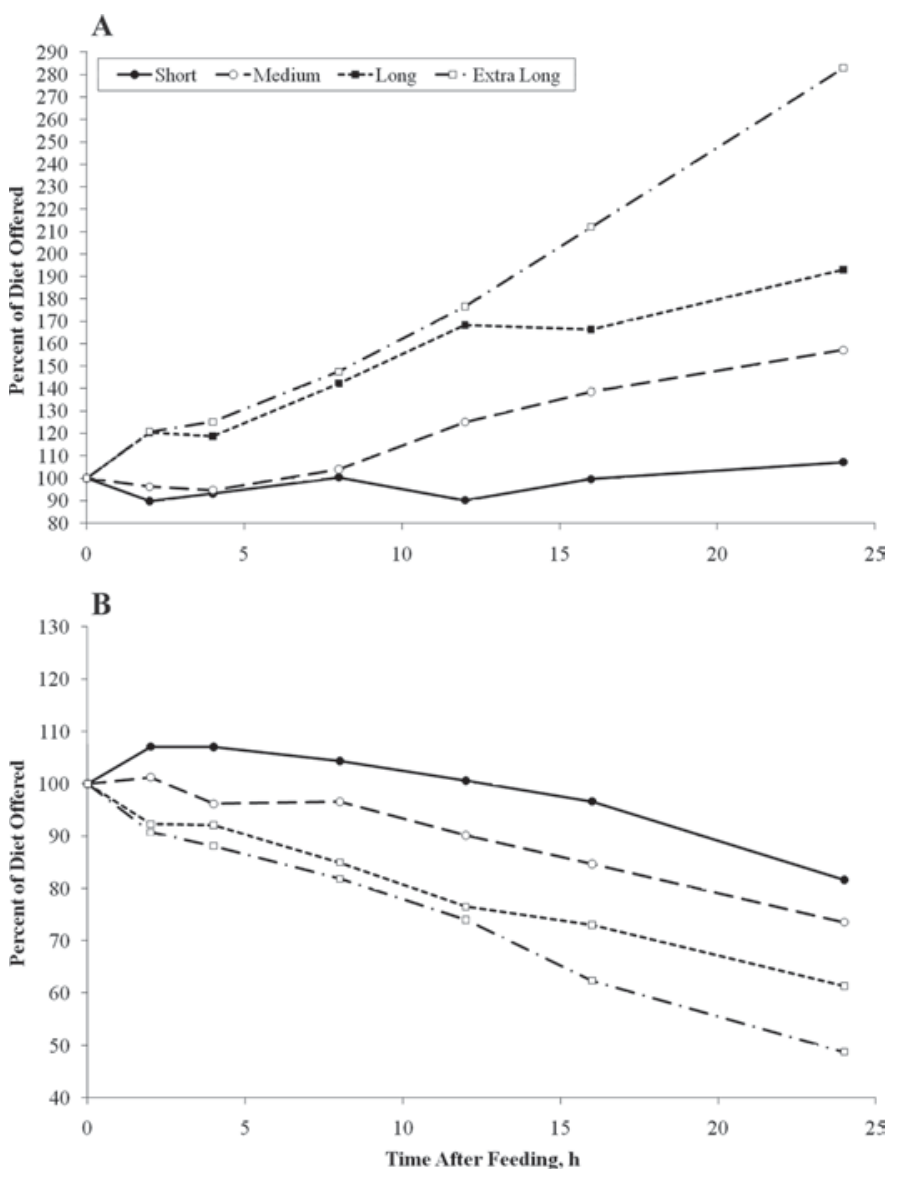

Figure 2. Effect of feeding TMR of increasing particle size on refusal particle distribution as a percentage of original diet. Selected data shown; 26.9-mm sieve (A) and pan (B).

$\mathrm{S}$ grass hay and XL grass hay. The M hay had lower $\mathrm{ADF}$ and NDF and higher NFC values than other hay lengths; this was probably due to individual bale variation. Although all bales were from the same field and cutting, each length of hay was composed of different bales. These differences however did not affect TMR chemical composition. Particle size distribution of the fed TMR also varied greatly (Table 2). The greatest differences were in the particle fraction $>26.9 \mathrm{~mm}$. The only particle fraction that did not show differences among diets was particles retained on the pan. Measured mean particle lengths for the top screen to calculate $\mathrm{X}_{\mathrm{gm}}$ were $74.8 \pm 6.6,84.5 \pm 2.6,105.7 \pm 9.1$, and $118.8 \pm 3.6$ (mean $\pm \mathrm{SD}, \mathrm{mm}$ ) for $\mathrm{S}, \mathrm{M}, \mathrm{L}$, and $\mathrm{XL}$ diets, respectively. Particle lengths (geometric mean \pm $\mathrm{SD}, \mathrm{mm} ; \mathrm{ASABE}, 2007)$ of the fed rations were $4.46 \pm$ $0.13,5.10 \pm 0.13,5.32 \pm 0.13$, and $5.84 \pm 0.13$ for $\mathrm{S}$, $\mathrm{M}, \mathrm{L}$, and XL diets, respectively. The $\mathrm{X}_{\mathrm{gm}}$ of the rations were approximately equally spaced with differences averaging $0.46 \mathrm{~mm}$ between each ration from $\mathrm{S}$ to XL; $\mathrm{S}_{\mathrm{gm}}$ increased linearly with increasing ration particle size. 
Chemical compositions were similar among the rations, with only slight differences in DM, which linearly increased with increasing particle size. It is interesting to note that although there were large differences in mean particle length among rations peNDF ${ }_{1.18}$ remained constant. This occurs because all particles $>1.65 \mathrm{~mm}$ are weighted equally regardless of length, a weakness of calculating peNDF this way. There was a linear trend for $\mathrm{peNDF}_{8.0}$ to increase with increasing TMR particle size but the numerical difference was small.

\section{Ration Sorting}

Figure 1 shows that the $\mathrm{X}_{\mathrm{gm}}$ of refusals increased in all rations throughout the day. The amount of change varied by diet; the shortest diet changed very little between feeding and removal of orts, whereas the longest diet had a very drastic change in $\mathrm{X}_{\mathrm{gm}}$ during the same period. This effect can also be seen in Figure 2, where the percentage of particle fractions in refusals in relation to their percentage in fed TMR is shown. The top screen percentages increased in all diets with very large increases in the longest 2 rations $(107,157$, 193, and 283\%; S, M, L, and XL). The pan percentages decreased in all rations, again with greater changes between TMR fed and TMR refused as the TMR particle size increased. The pan percentages after $24 \mathrm{~h}$ were 82 , 74,61 , and $49 \%$ of the amount in the fed TMR for the $\mathrm{S}, \mathrm{M}, \mathrm{L}$, and XL rations, respectively. Only graphs of the top screen and pan are shown because of space constraints, but the 2 largest screens showed very similar patterns, the middle 2 screens did not show substantial differences among the rations or from the original diet, and the bottom 2 fractions showed similar patterns. These results are supported by the finding that NDF concentration in refusals increased more in the longer rations throughout the day than did the shorter rations (Figure 3). In addition, the level of starch decreased in the 2 longest rations and remained unchanged or even increased in the 2 shorter rations. These data could lead to the conclusion that animals consumed very different amounts of starch and NDF during the day due to sorting activity. However, when the amount of these components consumed per day was calculated, rations had similar levels of NDF and starch intakes (Table 3). Cumulative sorting indices for particle size, NDF, and starch intake expressed as the actual intake of each component divided by the predicted intake of that component are shown in Figures 4 and 5. Sorting indices of $\mathrm{S}$ and $\mathrm{M}$ rations for the top screen were higher than those for L and XL rations at $8 \mathrm{~h}$ and less; after $8 \mathrm{~h}$ there were no differences among the rations. Pan sorting indices showed that at $2 \mathrm{~h}, \mathrm{~L}$ and XL were highest,
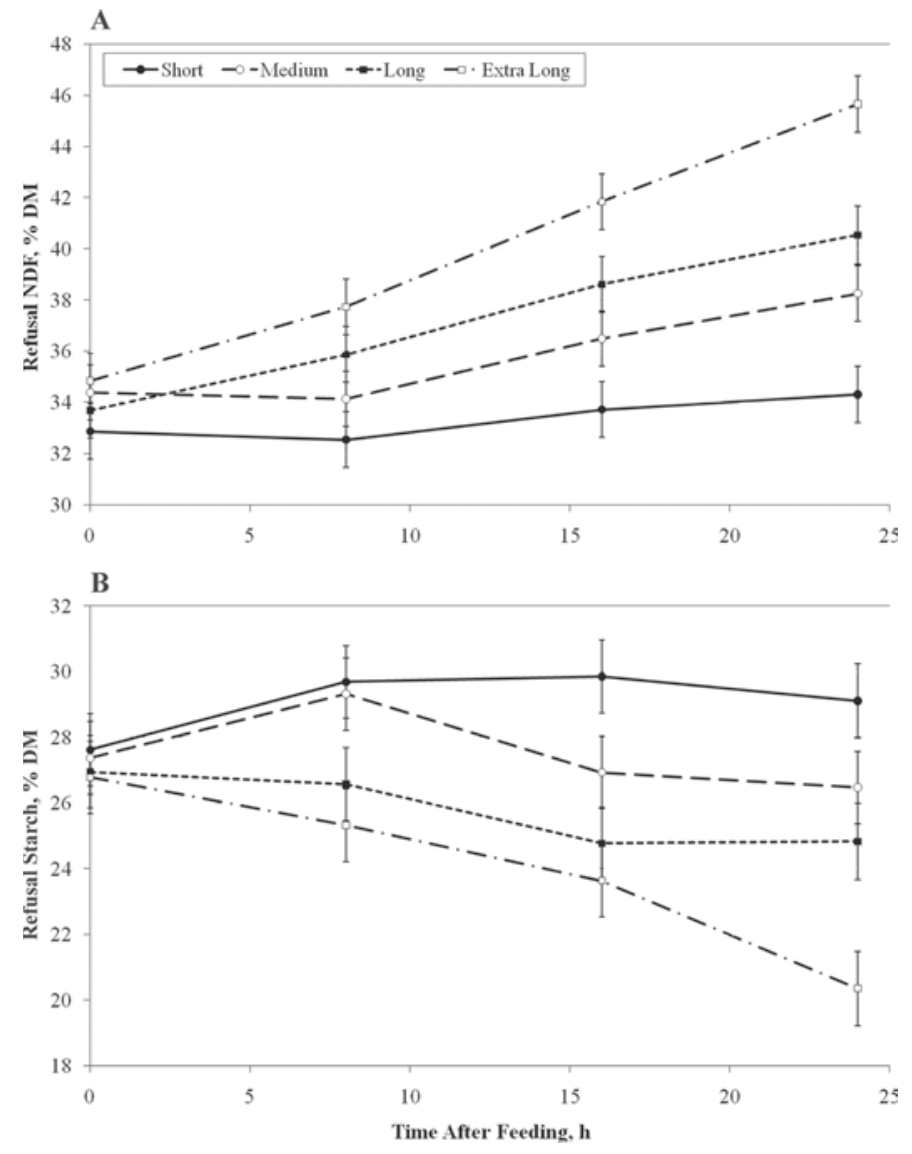

Figure 3. Effect of feeding TMR of increasing particle size on refusal NDF (A) and starch (B) concentration.

$\mathrm{M}$ was intermediate, and S was lowest. The differences diminished after $2 \mathrm{~h}$ and eventually disappeared by 12 h. Only the top screen and pan fractions are shown, but the top 3 screens showed similar patterns, the fourth screen did not show substantial differences among the rations, and the bottom 2 fractions showed similar patterns. The $\mathrm{S}$ and $\mathrm{M}$ rations had higher NDF sorting indices and lower starch sorting indices than the $\mathrm{L}$ and $\mathrm{XL}$ rations at $8 \mathrm{~h}$ after feeding. By $24 \mathrm{~h}$ after feeding, there were no longer differences among the 4 rations for NDF or starch sorting indices. Figure 6 shows the cumulative $\mathrm{X}_{\mathrm{gm}}$ selection index, which combines all 6 particle fractions to make an easier comparison. The $\mathrm{S}$ and $\mathrm{M}$ rations had much higher selection indices for the first $8 \mathrm{~h}$ than the $\mathrm{L}$ and XL rations; the ration being consumed was longer than the ration fed for $\mathrm{S}$ and $\mathrm{M}$ and shorter for L and XL. After $8 \mathrm{~h}$, the rations became much closer in values but remained different; at $24 \mathrm{~h}$ the longest 3 rations remained below 1 and $\mathrm{S}$ was equal to 1 . 
Table 3. Effect of feeding TMR containing short (S), medium (M), long (L), or extra long (XL) grass hay on DM, NDF, and starch intake at various times after feeding and total consumption (measured $24 \mathrm{~h}$ after feeding) of various sized particles

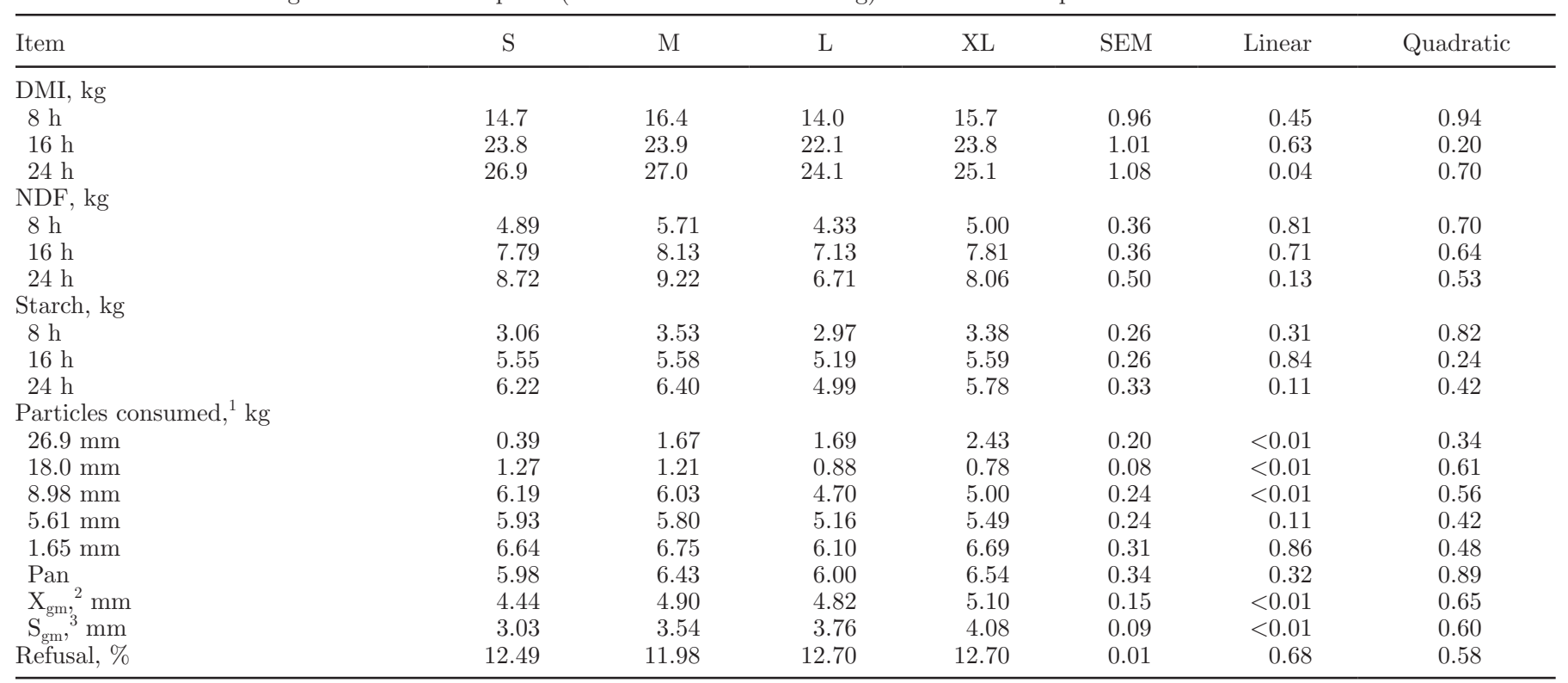

${ }^{1}$ Approximate equivalency to Penn State Particle Separator: top sieve $(26.9+18.0 \mathrm{~mm})$, middle sieve $(8.98 \mathrm{~mm})$, lower sieve $(5.61+1.65 \mathrm{~mm})$, and pan (pan).

${ }^{2} \mathrm{X}_{\mathrm{gm}}=$ geometric mean particle length determined by ASABE (2007).

${ }^{3} \mathrm{~S}_{\mathrm{gm}}=$ particle length standard deviation determined by ASABE (2007).

\section{Intake of DM, NDF, Starch, and Particle Fractions}

There was a linear trend for decreased DMI as TMR particle size increased (Table 3); this trend was probably due to increased gut fill associated with the bulkier diets, as has been noted previously (Kononoff and Heinrichs, 2003; Leonardi et al., 2005b). These results are contrary to other studies (Krause et al., 2002a; Beauchemin and Yang, 2005) that showed no effect of forage particle size on DMI. The diets had NDF and starch intakes that were not different despite very different sorting characteristics among the rations throughout the day. Analysis of intake of individual particle fractions revealed that intake of particles retained on the 26.9-mm sieve increased linearly from 0.39 to $2.43 \mathrm{~kg} / \mathrm{d}$ with increasing ration particle size, as seen in Table 3. In contrast, intake of particles retained on the 18.0- and 8.98-mm sieves showed a linear decrease as the particle size of the ration increased. Intake of particles retained on the 5.61-mm sieve was similar among rations. Intake of particles retained on the $1.65-\mathrm{mm}$ screen and the pan were also not different among rations, most likely influenced by the equal concentrate fed to all groups. The consumed $\mathrm{X}_{\mathrm{gm}}$ was much closer among rations than the $\mathrm{X}_{\mathrm{gm}}$ fed. Consumed $\mathrm{X}_{\mathrm{gm}}$ for all rations was between 4.44 and $5.10 \mathrm{~mm}$. This probably occurred because cows on the shorter rations made up for being offered fewer particles $>26.9 \mathrm{~mm}$ by increasing their intake of particles retained on the 18.0and 8.98-mm sieves. Also, intake of NDF and starch remained similar among rations despite different intakes of particle fractions because the particles retained on the top 3 sieves that varied in intakes were primarily grass hay, and thus had similar composition. Finally, refusal percentages met or slightly exceeded the goal of $10 \%$ and were not different among rations.

\section{Chewing Activity}

Observed meal criteria (Table 4) were 7.6, 13.8, 10.5, and 11.2 min for $\mathrm{S}, \mathrm{M}, \mathrm{L}$, and XL rations, respectively, with $\mathrm{S}$ meal criterion being significantly less than the other rations. The modes of the intrameal intervals were found to be $13.7,13.5,14.1$, and $12.0 \mathrm{~s}$ for $\mathrm{S}, \mathrm{M}, \mathrm{L}$, and XL, respectively, and were not different from each other. The modes of the intermeal intervals were 51.8, 72.1, 58.7, and 68.4 min for S, M, L, and XL, with S having a shorter interval than the other diets. The DMI per meal was determined to be similar among diets and averaged $2.35 \mathrm{~kg} /$ meal. There were no differences among diets for ruminating, eating, or total chewing time per day for all meal criteria and averaged 515, 388, and $903 \mathrm{~min} / \mathrm{d}$, respectively (Table 5). When chewing activity was expressed as time per kilogram of DMI, there were significant linear contrasts for increased ruminating, eating, and total chewing time per kilogram 

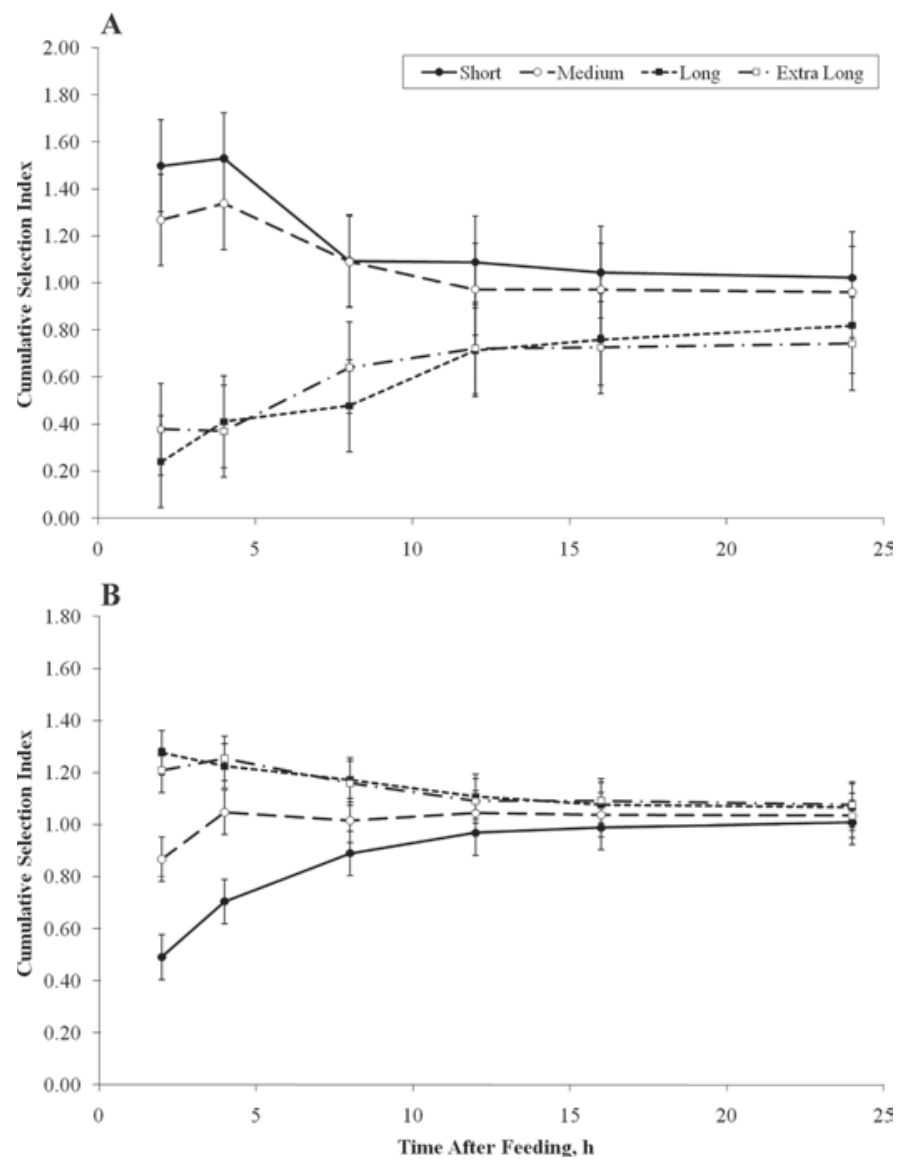

Figure 4. Effect of feeding TMR of increasing particle size on cumulative particle size selection index. Selected data shown; $26.9-\mathrm{mm}$ sieve (A) and pan (B).

of DMI as TMR particle size increased and averaged 20.6, 15.5, and $36.0 \mathrm{~min} / \mathrm{kg}$, respectively. Ruminating, eating, and total chewing activity values expressed as minutes per day were higher than those reported in other studies (Beauchemin et al., 2003; Kononoff and Heinrichs, 2003; Beauchemin and Yang, 2005). However, when these data were expressed as minutes per kilogram of DMI they were found to be similar to the data reported in these same studies. This may be explained by the fact that the DMI in this study was, on average, $4.4 \mathrm{~kg} / \mathrm{d}$ higher than these 3 other studies, increasing the total amount of daily chewing activity. Chewing activity expressed as minutes per day was probably not different among rations because DMI decreased linearly while chewing activity $(\mathrm{min} / \mathrm{kg}$ of DMI) increased linearly with increasing TMR particle size, effectively nullifying the changes. The mean total time that chewing activity was recorded was not different among rations and was $23.8 \mathrm{~h}$. Chewing activity was also expressed as number of chews per day and chews per kilogram of DMI. Again, there were no differences among diets for ruminating, eating, and total chewing when calculated on a daily basis. There were no changes in number of ruminating chews per kilogram of DMI, but there was a linear trend for number of eating and total chews per kilogram of DMI to increase as TMR particle size increased. There were no differences among diets in number of meals eaten per day. Similar to chewing time per day, number of boli per day showed no differences among diets, but when expressed as boli per kilogram of DMI, there was a linear increase with increasing TMR particle size.

Chewing data were also analyzed using 5-min and 7-min meal criteria. Eating and total chewing time increased slightly as the length of the meal criteria interval increased. The number of eating and total chews increased slightly as length of the meal criteria interval increased. Number of meals per day decreased as the length of the meal criteria increased. Therefore, these data show that exact meal criterion used is not important because there are only small changes in values of variables and there are no changes to conclusions made based on these values.
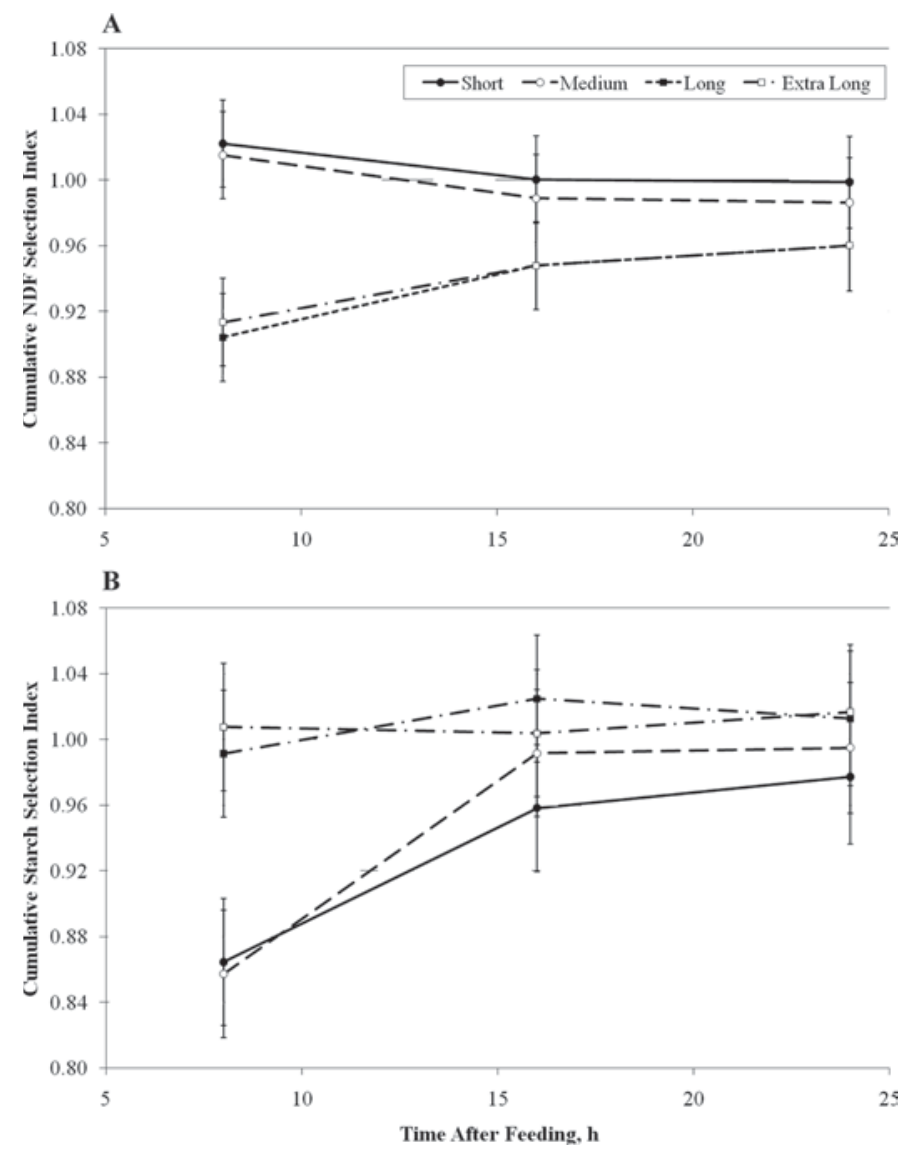

Figure 5. Effect of feeding TMR of increasing particle size on cumulative NDF (A) and starch (B) selection indices. 


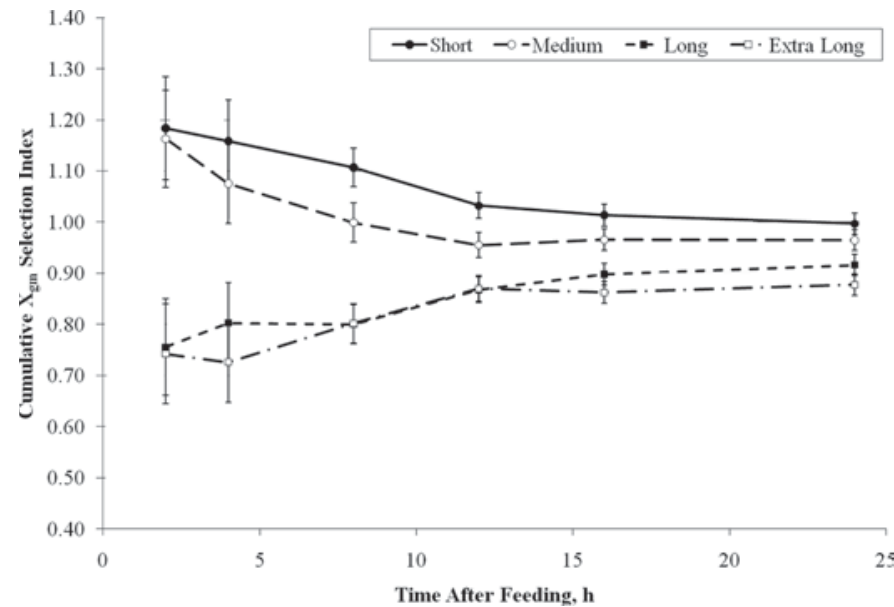

Figure 6. Effect of feeding TMR of increasing particle size on cumulative geometric mean length $\left(\mathrm{X}_{\mathrm{gm}}\right)$ selection index.

\section{Rumen Characteristics}

The weighted mean rumen $\mathrm{pH}$ was similar among rations (Table 6) but there was a trend for a quadratic contrast for these data. Kononoff and Heinrichs (2003) found a similar quadratic contrast when increasing alfalfa haylage particle size in TMR. The average weighted mean for all diets was 5.98. This was similar to results from some studies (Krause et al., 2002b; Beauchemin et al., 2003), higher than some (Beauchemin and Yang, 2005), and lower than others (Kononoff et al., 2003b; Leonardi et al., 2005b). No differences were found in the minimum rumen $\mathrm{pH}$ among rations and average minimum $\mathrm{pH}$ for all rations was 5.42. There was a linear tendency for decreasing maximum rumen $\mathrm{pH}$ with increasing ration particle size. Perhaps the intake of starch at any one time was not great enough to overcome the buffering capacity of the rumen with a large amount of forage still retained from the previous day. This slow digesting fiber allows the cow to create a more uniform rumen environment than the actual intake of feed would allow otherwise. The weighted mean, minimum, and maximum $\mathrm{NH}_{3}$ concentrations were found to have no significant contrasts among rations; the mean averaged $8.3 \mathrm{mg} / \mathrm{dL}$. These results are similar to what was found by Kononoff et al. (2003b). The concentrations of acetate, propionate, butyrate, valerate, isovalerate, isobutyrate were also shown to have no significant contrasts among diets. Concentrations of all VFA measured were similar to those found by Kononoff and Heinrichs (2003)

\section{Milk Production and Composition}

Milk production averaged $38.7 \mathrm{~kg} / \mathrm{d}$ and the rations had no effect on milk, FCM, fat, protein, or lactose yields (Table 7 ). Milk fat percentage was similar among diets, as was milk protein percentage. These results are in agreement with some studies that found that changes in forage particle size did not affect milk production or components (Krause et al., 2002a; Beauchemin et al., 2003; Bhandari et al., 2008) but are in disagreement with others that found that changes in forage particle size do influence milk production or components (Kononoff et al., 2003b; Leonardi et al., 2005b). There were linear trends for lactose and MUN to decrease with increasing ration particle size, but there were only slight numerical differences. There was a significant quadratic contrast for SCC but the reason for the tendency is not apparent. One cow was removed from the milk production and composition analysis because of chronically high SCC. Removing this cow from the analysis decreased the average SCC by 135,350 cells $/ \mathrm{mL}$ and increased average percentage fat by 0.09 ; however, it did not change the conclusions for any production parameters.

Table 4. Observed meal characteristics for diets containing short (S), medium (M), long (L), or extra long (XL) grass hay

\begin{tabular}{llllll}
\hline Item & $\mathrm{S}$ & $\mathrm{M}$ & $\mathrm{L}$ & $\mathrm{XL}$ & $\mathrm{SEM}^{1}$ \\
\hline Intrameal interval, & ${ }^{2} \mathrm{~s}$ \\
$\quad$ Mode & & & & & \\
$95 \%$ CI & 13.7 & 13.5 & 14.1 & 12.0 & - \\
Intermeal interval, ${ }^{3}$ min & $16.8-11.2$ & $16.5-11.0$ & $17.2-11.5$ & $14.7-9.8$ & - \\
$\quad$ Mode & $51.8^{\mathrm{b}}$ & $72.1^{\mathrm{a}}$ & $58.7^{\mathrm{a}}$ & $68.4^{\mathrm{a}}$ & - \\
$95 \%$ CI & $70.1-38.3$ & $97.6-53.3$ & $79.4-43.4$ & $92.5-50.5$ & - \\
Meal criterion, min & $7.6^{\mathrm{b}}$ & $13.8^{\mathrm{a}}$ & $10.5^{\mathrm{a}}$ & $11.2^{\mathrm{a}}$ & - \\
$95 \%$ CI & $10.0-5.7$ & $18.3-10.4$ & $14.0-8.0$ & $14.8-8.4$ & - \\
DMI $/$ meal, ${ }^{4} \mathrm{~kg}$ & 2.34 & 2.49 & 2.28 & 2.30 & 0.32 \\
\hline
\end{tabular}

\footnotetext{
${ }^{\mathrm{a}, \mathrm{b}}$ Means within a row with different superscripts differ after transforming $(P<0.05)$.

${ }^{1}$ For model output, back-transformed $95 \%$ confidence intervals are shown.

${ }^{2}$ Intrameal interval $=$ bout of no eating within meals.

${ }^{3}$ Intermeal interval $=$ bout of no eating outside of meals.

${ }^{4}$ Calculated based on daily DMI.
} 
Table 5. Effect of feeding TMR containing short (S), medium (M), long (L), or extra long (XL) grass hay on chewing behavior as determined by observed meal criteria ${ }^{\mathrm{T}}$

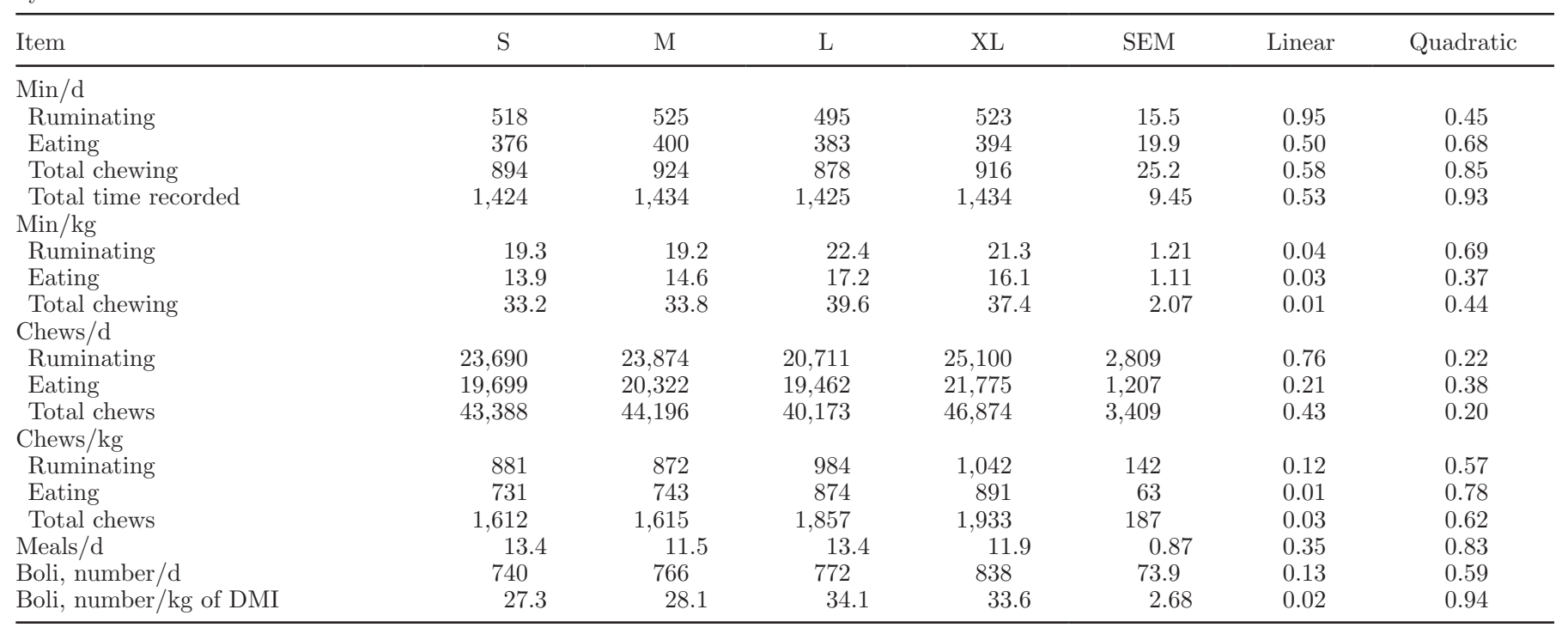

${ }^{1}$ Observed meal criteria use intervals predicted from current data set.

\section{CONCLUSIONS}

In this experiment, 4 diets that varied only in the particle size of their grass hay were fed to lactating dairy cows to measure differences in sorting activity and the effect of these differences on production parameters. Great differences were observed among rations when sorting activity was determined by the change in composition of refusals (particle size, NDF, and starch) compared with the ration fed. However, actual intake of these components after $24 \mathrm{~h}$ was similar for all rations and as a result milk production, milk components and rumen characteristics were similar among the rations. Therefore, cows were essentially receiving different rations throughout the day, but the final daily outcome was the not different. When measuring sorting activity in lactating dairy cattle it is important to consider not only the composition of the orts (which comprise only a small percentage of the daily intake), but also the actual intakes of various ration components. In addition, although the diets fed varied greatly in $\mathrm{X}_{\mathrm{gm}}$, the $\mathrm{X}_{\mathrm{gm}}$ of what was consumed by cows were very similar. Cows on the $\mathrm{S}$ ration ate a ration similar in $\mathrm{X}_{\mathrm{gm}}$ to what was offered, and cows on all other rations ate a shorter ration than what was offered. Because the ration the cows actually consumed had similar $\mathrm{X}_{\mathrm{gm}}$ and the cows sorted the ration that was offered, perhaps these cows were sorting to achieve a desired $\mathrm{X}_{\mathrm{gm}}$. If this is the case, a ration with the proper $\mathrm{X}_{\mathrm{gm}}$ may be able to limit or eliminate ration sorting by lactating cows.

Table 6. Effect of feeding TMR containing short (S), medium (M), long (L), or extra long (XL) grass hay on rumen fermentation

\begin{tabular}{|c|c|c|c|c|c|c|c|}
\hline Item & $\mathrm{S}$ & M & $\mathrm{L}$ & XL & SEM & Linear & Quadratic \\
\hline Weighted average $^{1}$ & 5.96 & 6.05 & 5.98 & 5.92 & 0.05 & 0.39 & 0.07 \\
\hline Minimum & 5.36 & 5.45 & 5.43 & 5.44 & 0.05 & 0.32 & 0.41 \\
\hline \multicolumn{8}{|l|}{$\mathrm{NH}_{3}, \mathrm{mg} / \mathrm{dL}$} \\
\hline Weighted average & 7.56 & 8.02 & 8.01 & 9.42 & 1.03 & 0.21 & 0.57 \\
\hline Minimum & 2.10 & 2.76 & 3.20 & 5.04 & 1.04 & 0.08 & 0.51 \\
\hline \multicolumn{8}{|c|}{ VFA weighted average, $\mu M / \mathrm{mL}$} \\
\hline Acetate & 84.6 & 84.6 & 84.2 & 85.6 & 1.71 & 0.50 & 0.44 \\
\hline Propionate & 31.8 & 30.3 & 31.8 & 32.7 & 2.39 & 0.70 & 0.54 \\
\hline Butyrate & 15.4 & 15.7 & 16.4 & 15.9 & 0.70 & 0.51 & 0.58 \\
\hline Valerate & 2.72 & 2.74 & 2.93 & 3.11 & 0.14 & 0.07 & 0.62 \\
\hline Isovalerate & 2.45 & 2.46 & 2.46 & 2.55 & 0.11 & 0.31 & 0.55 \\
\hline Isobutyrate & 1.90 & 1.85 & 1.86 & 1.98 & 0.06 & 0.29 & 0.11 \\
\hline
\end{tabular}

${ }^{1}$ Weighted averages determined by calculating the area under the response curve according to the trapezoidal rule (Shipley and Clark, 1972). 
Table 7. Effect of feeding TMR containing short (S), medium (M), long (L), or extra long (XL) grass hay on milk production and components $^{1}$

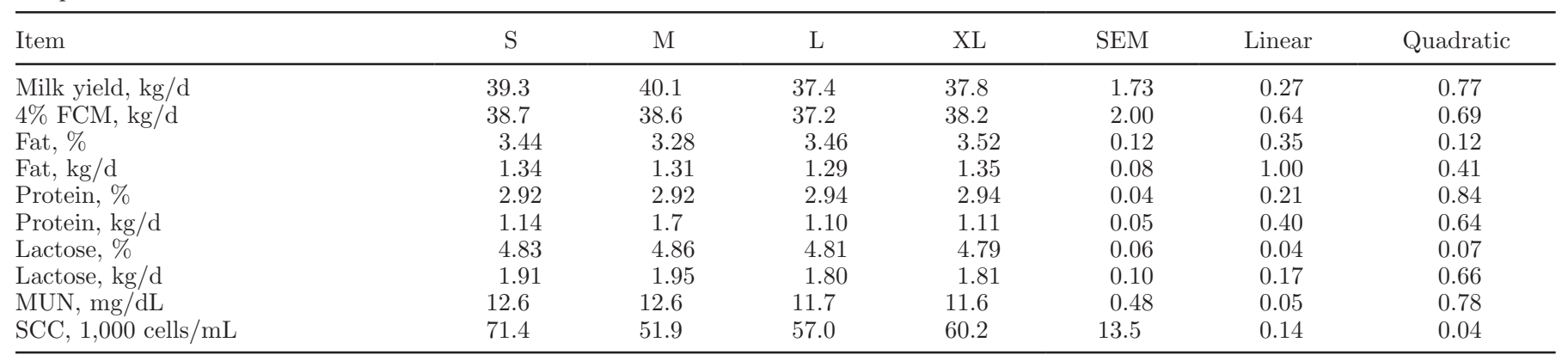

${ }^{1}$ One cow was removed from analysis due to chronic high SCC.

\section{ACKNOWLEDGMENTS}

This research was supported in part by agricultural research funds administered by The Pennsylvania Department of Agriculture.

\section{REFERENCES}

Allen, M. S. 1997. Relationship between fermentation acid production in the rumen and the requirement for physically effective fiber. J. Dairy Sci. 80:1447-1462.

ASABE. 2007. Method of determining and expressing particle size of chopped forage materials by screening. ANSI/ASAE. S424.1:663665.

Bailey, C. B. 1961. Saliva secretion and its relation to feeding in cattle. Br. J. Nutr. 15:443-451

Balch, C. C. 1971. Proposal to use time spent chewing as an index of the extent to which diets for ruminants possess the physical property of fibrousness characteristic of roughages. Br. J. Nutr. $26: 383-392$.

Beauchemin, K. A., L. Eriksen, P. Norgaard, and L. M. Rode. 2008. Short communication: Salivary secretion during meals in lactating dairy cattle. J. Dairy Sci. 91:2077-2081.

Beauchemin, K. A., and W. Z. Yang. 2005. Effects of physically effective fiber on intake, chewing activity, and ruminal acidosis for dairy cows fed diets based on corn silage. J. Dairy Sci. 88:2117-2129.

Beauchemin, K. A., W. Z. Yang, and L. M. Rode. 2003. Effects of particle size of alfalfa-based dairy cow diets on chewing activity, ruminal fermentation, and milk production. J. Dairy Sci. 86:630643.

Bhandari, S. K., S. Li, K. H. Ominski, K. M. Wittenberg, and J. C. Plaizier. 2008. Effects of the chop lengths of alfalfa silage and oat silage on feed intake, milk production, feeding behavior, and rumen fermentation of dairy cows. J. Dairy Sci. 91:1942-1958.

Broderick, G. A., and J. H. Kang. 1980. Automated simultaneous determination of ammonia and total amino acids in ruminal fluid and in vitro media. J. Dairy Sci. 63:64-75.

Dado, R. G., and M. S. Allen. 1993. Continuous computer acquisition of feed and water intakes, chewing, reticular motility, and ruminal $\mathrm{pH}$ of cattle. J. Dairy Sci. 76:1589-1600.

DeVries, T. J., K. A. Beauchemin, and M. A. G. von Keyserlingk. 2007. Dietary forage concentration affects the feed sorting behavior of lactating dairy cows. J. Dairy Sci. 90:5572-5579.

Kenward, M. G., and J. H. Roger. 1997. Small sample inference for fixed effects from restricted maximum likelihood. Biometrics 53:983-997.

Knudsen, K. E. B. 1997. Carbohydrate and lignin contents of plant materials used in animal feeding. Anim. Feed Sci. Technol. $67: 319-338$.
Kononoff, P. J., and A. J. Heinrichs. 2003. The effect of reducing alfalfa haylage particle size on cows in early lactation. J. Dairy Sci. 86:1445-1457.

Kononoff, P. J., A. J. Heinrichs, and D. R. Buckmaster. 2003a. Modification of the Penn State forage and total mixed ration particle separator and the effects of moisture content on its measurements. J. Dairy Sci. 86:1858-1863.

Kononoff, P. J., A. J. Heinrichs, and H. A. Lehman. 2003b. The effect of corn silage particle size on eating behavior, chewing activities, and rumen fermentation in lactating dairy cows. J. Dairy Sci $86: 3343-3353$

Kononoff, P. J., H. A. Lehman, and A. J. Heinrichs. 2002. Technical note: A comparison of methods used to measure eating and ruminating activity in confined dairy cattle. J. Dairy Sci. 85:18011803.

Krause, K. M., D. K. Combs, and K. A. Beauchemin. 2002a. Effects of forage particle size and grain fermentability in midlactation cows. I. Milk production and diet digestibility. J. Dairy Sci. 85:19361946.

Krause, K. M., D. K. Combs, and K. A. Beauchemin. 2002b. Effects of forage particle size and grain fermentability in midlactation cows. II. Ruminal pH and chewing activity. J. Dairy Sci. 85:19471957.

Leonardi, C., and L. E. Armentano. 2003. Effect of quantity, quality, and length of alfalfa hay on selective consumption by dairy cows. J. Dairy Sci. 86:557-564.

Leonardi, C., F. Giannico, and L. E. Armentano. 2005a. Effect of water addition on selective consumption (sorting) of dry diets by dairy cattle. J. Dairy Sci. 88:1043-1049.

Leonardi, C., K. J. Shinners, and L. E. Armentano. 2005b. Effect of different dietary geometric mean particle length and particle size distribution of oat silage on feeding behavior and productive performance of dairy cattle. J. Dairy Sci. 88:698-710.

Littell, R. C., P. R. Henry, and C. B. Ammerman. 1998. Statistical analysis of repeated measures data using SAS procedures. J. Anim. Sci. 76:1216-1231.

Maekawa, M., K. A. Beauchemin, and D. A. Christensen. 2002. Effect of concentrate level and feeding management on chewing activities, saliva production, and ruminal $\mathrm{pH}$ of lactating dairy cows. J. Dairy Sci. 85:1165-1175.

Mooney, C. S., and M. S. Allen. 2007. Effect of dietary strong ions on chewing activity and milk production in lactating dairy cows. J. Dairy Sci. 90:5610-5618.

NRC. 2001. Nutrient Requirements of Dairy Cattle. 7th rev. ed. Natl. Acad. Sci., Washington, DC.

Nocek, J. E. 1997. Bovine acidosis: Implications on laminitis. J. Dairy Sci. 80:1005-1028.

Robson, D. S. 1959. A simple method for constructing orthogonal polynomials when the independent variable is unequally spaced. Biometrics 15:187-191.

Rutter, S. M. 2000. Graze: A program to analyze recordings of the jaw movements of ruminants. Behav. Res. Methods Instrum. Comput. $32: 86-92$. 
Rutter, S. M., R. A. Champion, and P. D. Penning. 1997. An automatic system to record foraging behaviour in free-ranging ruminants. Appl. Anim. Behav. Sci. 54:185-195.

SAS Institute. 2006. SAS User's Guide. Statistics. Version 9.1.3. SAS Inst. Inc., Cary, NC.

Shipley, R. A., and R. E. Clark. 1972. Tracer Methods for In Vivo Kinetics. Academic Press, New York, NY.

Sudweeks, E. M., L. O. Ely, D. R. Mertens, and L. R. Sisk. 1981. Assessing minimum amounts and form of roughages in ruminant diets: Roughage value index system. J. Anim. Sci. 53:1406-1411.

Tolkamp, B. J., D. J. Allcroft, E. J. Austin, B. L. Nielsen, and I. Kyriazakis. 1998. Satiety splits feeding behaviour into bouts. J. Theor. Biol. 194:235-250.
Van Soest, P. J., J. B. Robertson, and B. A. Lewis. 1991. Methods for dietary fiber, neutral detergent fiber, and nonstarch polysaccharides in relation to animal nutrition. J. Dairy Sci. 74:3583-3597.

Yang, C.-M. J., and G. A. Varga. 1989. Effect of three concentrate feeding frequencies on rumen protozoa, rumen digesta kinetics, and milk yield in dairy cows. J. Dairy Sci. 72:950-957.

Yeates, M. P., B. J. Tolkamp, D. J. Allcroft, and I. Kyriazakis. 2001. The use of mixed distribution models to determine bout criteria for analysis of animal behaviour. J. Theor. Biol. 213:413-425. 